\title{
Renegotiation of Software Outsourcing Contracts
}

\author{
He Huanga, Minhui Hua, Robert J. Kauffman ${ }^{\mathrm{b}}$ and Hongyan $\mathrm{Xu}^{\mathrm{a}}$ \\ ${ }^{a}$ School of Economics and Business Administration, Chongqing University, China \\ ${ }^{\mathrm{b}}$ School of Information Systems, Singapore Management University, Singapore \\ \{huanghe,hu_minhui, xuhongyan\}@cqu.edu.cn; kauffman@smu.edu.sg
}

\begin{abstract}
Fixed-price and time-and-materials contracts are commonly-used contract forms by clients in software outsourcing. The two parties, client and provider, usually renegotiate the testing time after system development occurs. This research investigates the impacts of such renegotiation on the client's contract choice. Our analysis shows that under both contract forms, renegotiation can incentivize the provider's effort, and this effect becomes more influential when the provider has higher bargaining power. Compared with a fixedprice contract, a time-and-materials contract can stimulate the provider's effort based on the terms for monitoring and reimbursement. The results suggest that when the provider has high bargaining power, the client will prefer a fixed-price contract. But when the provider has low bargaining power and the cost of monitoring is low, the client will prefer a time-andmaterials contract. When the provider has low bargaining power and the cost of monitoring is high though, the client will prefer a fixed-price contract.
\end{abstract}

\section{Introduction}

Software outsourcing has experienced tremendous growth over the last two decades [21] and Technavio's analysts forecast the global IT outsourcing market to grow at a compound annual rate of 5.84\% from 2014 to 2019 [28]. In 2016, 951 software outsourcing contracts worth USD 102.4 billion were signed worldwide [18]. In practice, the software outsourcing process is comprised of three stages: development, testing and maintenance. Practitioners recognize that software outsourcing consists of various uncertainties, such as the volatility of software code [19] and the transformation of IT landscape [24].

In software outsourcing, two kinds of contracts are commonly used between the client and the provider: fixed-price contracts and time-and-materials contracts [13]. A fixed-price contract consists of a predetermined payment for system development, testing and maintenance services from the provider. Besides payment for the services of the provider, time-and-materials contracts include an extra fee for the provider's effort, especially in system development. Due to the unobservability and non-contractibility of effort, in a time-and-materials contract, the client needs to monitor the provider's effort to determine the appropriate compensation for what it has done.

Apart from contracts to activate the outsourcing process, due to the associated uncertainties, we also observe that the two parties usually renegotiate the system testing time after system development. For example, the Kansas Department of Health and Environment signed a fixed-price contract with Accenture, and after the system was developed, they extended the contract for five years to test and debug the system [22]. Also, the British Columbia, Canada. Ministry of Health signed a time-and-materials contract with IBM and revised the contractual terms around timeline and defect remediation, requiring IBM to resolve system bugs during testing.

Renegotiation of testing time not only addresses the uncertainties in system development, but also affects the provider's development effort since testing time is mainly determined by the quality of the effort. Further, testing time is also a vital decision in software outsourcing to balance the trade-off between testing and maintenance costs after the system has been developed. If testing time is short, many critical bugs may remain undiscovered, which results in high maintenance cost, but prolonged testing leads to the delays in system release, which is costly as well. Observers suggest that in the fast-evolving IT market, a fixed-price contract with renegotiation is more appropriate [23]. However, nobody likes to renegotiate a contract with a provider [26] and so time-and-materials contracts have become popular because they reduce the possibility of renegotiation [17].

The above facts in software outsourcing pose interesting challenges for the client: Which contract form should be chosen when the client renegotiates with the provider on testing time after system development? To address the above question, we set up a multi-stage model in which a client outsources a cus- 
tomized information system from an IT service provider. We examine two contract types - a fixed-price contract and a time-and-materials contract - and focus on the impacts of testing time renegotiation on the client's preference.

Our analysis will show that, compared with a fixed-price contract, a time-and-materials contract can stimulate the provider's effort through monitoring. For these two contract types, renegotiation can incentivize the provider's effort, and as the provider's bargaining power in renegotiation increases, the latter is more willing to exert effort. When the provider has high bargaining power, renegotiation incentivizes the provider and the client will prefer a fixed-price contract. When the provider has low bargaining power and the per unit cost of monitoring is low though, the client will use monitoring as a complement to stimulate the provider and select a time-and-materials contract. When the provider has low bargaining power and the per unit cost of monitoring is high, renegotiation will lead to high monitoring cost, which reduces the client's profit in a time-and-materials contract. So a client will be better off choosing a fixed-price contract.

Section 2 reviews the relevant literature. Section 3 describes the model settings. Section 4 examines fixed-price contract and time-and-materials contract respectively. Section 5 analyzes the client's contract choice. Section 6 summarizes the findings and discusses modeling limitations and further research.

\section{Literature Review}

There has been increasing interest on software and IT outsourcing contracts in the IS literature. Dey et al. [10] and Cezar et al. [6] presented contract-theoretic models to analyze how to motivate the effort from provider(s). Lee et al. [20] examined the contract performance when both the client and the provider make efforts toward a common IT system. In addition, fixedprice and time-and-materials contracts are two typical software outsourcing arrangements. Previous research compares the differences between the two contracts in transaction costs $[3,8]$ and incentive mechanisms [13]. However, almost all the analyses mentioned above viewed software outsourcing contracts as complete. In practice, contracting for software development outsourcing is inevitably incomplete [3] because it typically involves unforeseen contingencies [10], noncontractible investments and behaviors [27], and immeasurable performance [11]. Bhattacharya et al. [4] studied incomplete software outsourcing contracts with renegotiation, but they focused on designing a renegotiation-proof contract. Benaroch et al. [2] mod- eled the implications of including a back-sourcing renegotiation option in a software outsourcing contract and specified the cost and value effects for the client and the provider. We will analyze the performance of incomplete software outsourcing contracts and investigate the impact of renegotiation on the client's preferences for a fixed-price contract or a time-and-materials contract.

The economics literature on renegotiation is vast. Bolton and Dewatripont [5] identified two streams: renegotiation under adverse selection and renegotiation under moral hazard. In the former, a potential participant does not know the other party's type before signing a contract. So contracts that are vulnerable to renegotiation tend to be less efficient in solving the asymmetric information problem between trading partners. Contracts that require the participants to commit to not renegotiate are better in this respect $[9,14]$. In the latter, if the parties can take unilateral actions after signing a contract, then the main issue is the hold-up problem, in which the investing party fears expropriation of the investment benefits by its contracting partner in renegotiation, leading to underinvestment $[7,12]$. Our work belongs to the latter stream but differs from it somewhat. Although the hold-up problem exists in both fixed-price contract and time-and-materials contract, we will report that renegotiation may offer the provider additional incentive to invest in making more service-related effort.

This research also relates to the literature on software reliability. The Goel-Okumoto non-homogeneous Poisson process model is the most commonly-used software reliability prediction model [16]. Using this model as a starting point, Pham and Zhang [25] presented a software reliability-cost model to determine the optimal testing time. Jiang et al. [15] separated testing stopping time from system release time. They considered testing as continuing during system operation, that is, post-release testing. August and Niculescu [1] further examined the impact of software demand on post-release testing. In addition, Jiang et al. [16] considered both software reliability and marketrelated benefits and derived not only the optimal testing time but also the optimal number of testers. However, an implicit assumption made in all these studies above is that the system would be developed completely. They ignored that the provider also must make additional effort in the system development process. As a result, we will consider both the development and testing stages. After the provider develops the system, the parties may renegotiate testing time before doing this work. 


\section{Model}

Consider a setting in which a client outsources a customized information system from an IT service provider. The outsourcing services offered by the provider include three stages: system development, system testing and system maintenance. In the system development stage, the provider develops the system based on the prototype system, and the system quality is indicated by the number of bugs [10]. Assume the prototype system has an initial number of bugs $N_{0}$, and the provider can exert effort $e \in\left\{e_{L}, e_{H}\right\}\left(e_{L}<e_{H}\right)$ to decrease the bugs to $N=N_{0}-e+\varepsilon$, where $\varepsilon$ is a uniformly-distributed random variable on $[-\varphi, \varphi]$. Since there are always bugs that can be detected, we assume $N_{0}-e_{H}-\varphi>0$. The cost of the development effort $e$ to the provider is $c e^{2}$, where $c$ is the provider's development efficiency. We assume that the development time, which is decided on the basis of the provider's past experience, is constant. The random noise $\varepsilon$ will be realized after the provider finishes system development, so the number $N$ can be observed when system development ends.

In the system testing stage, the provider spends time $t$ to detect system bugs with cost $k t$, and this process satisfies the properties of the Goel-Okumoto model for software reliability, so the expected number of undetected bugs $\theta(t)$ for testing time $t$ is:

$$
\theta(t)=N \exp (-\lambda t),
$$

where $\lambda$ represents the failure rate of each bug. The cost of fixing bugs detected during testing is $a(N-\theta(t))$ for the provider, where $a$ is the cost of fixing one bug in this stage.

In the system maintenance stage, the system is delivered to the client and put into operation. The cost of maintenance is incurred by the provider when system failure occurs during operation. It includes the direct cost associated with identifying and fixing the bugs, the loss of revenue due to system downtime, and other costs. This cost also depends on the number of undetected bugs $\theta(t)$. This is considered to be higher than the cost of fixing the same bugs if they are detected during the testing stage [15]. To facilitate the inclusion of this observation, we denote the cost of maintenance as $(a+b) \theta(t)$ for the provider, where $b$ is the added cost per bug during maintenance compared with that during testing.

\footnotetext{
${ }^{1}$ On the cost side, $k$ represents the marginal cost of testing. On the benefit side, since $\partial(b N \exp (-\lambda t)) / \partial t=-\lambda b N \exp (-\lambda t), \lambda b N$
}

Based on the above assumptions, the expected total cost for the provider is comprised of four parts:

$$
C=c e^{2}+k t+a(N-\theta(t))+(a+b) \theta(t),
$$

From Equation 1, this also can be expressed as:

$$
C=c e^{2}+k t+a N+b N \exp (-\lambda t)
$$

To exclude the unrealistic case in which testing time is negligible, we assume $\lambda b N>k$ to ensure the marginal benefit of testing is greater than its marginal cost. ${ }^{1}$

The utility of the system to the client decreases with the total number of system bugs. Therefore, the total utility of the client can be expressed as:

$$
U=V-u N
$$

where $V$ is the baseline utility if the system is bugfree, and $u$ is the client's sensitivity to bugs in the system. Further, after the system is developed and uncertainty associated with $\varepsilon$ is resolved, the initial testing time determined by the expected total number of bugs may not be optimal. So after observing the realized $N$ , the client and the provider have incentives to renegotiate the initial testing time $t$ to $\tilde{t}$. The two parties will split the extra social surplus increment generated by the renegotiation, a renegotiation surplus. The shares of the renegotiation surplus obtained by the provider and the client are $\alpha$ and 1- $\alpha$. Here, these also represent the relative bargaining power of the provider and the client in renegotiation.

There are two contract types that the client can use to initiate software outsourcing with the provider: a fixed-price contract or a time-and-materials contract. In a fixed-price contract, a predetermined price, $F_{F P}$, is paid to the provider for system development, testing and maintenance services. In a time-and-materials contract, besides the payment for the services of the provider, $F_{T M}$, the client also must pay an extra fee for the provider's effort. Thus, the transfer from the client to the provider in a time-and-materials contract is $F_{T M}+r \hat{e}$, where $\hat{e} \in\left\{e_{L}, e_{H}\right\}$ is the effort that the provider reports and $r$ is the reward based on effort. Since the provider's effort level $e$ is usually unobservable and non-contractible, the client must resort to monitoring the provider to verify the reported effort $\hat{e}$. The client's monitoring policy $\phi$ is chosen on a scale of $[0,1]$, which corresponds to the monitoring probability of effort made. A higher value of $\phi$ indicates that the client will monitor a larger number of documents and processes. Similar to Dey et al. [10], the monitoring cost to the client depends on the monitoring policy $w \phi$

represents the marginal benefit of testing, because $\lambda N$ is the expected rate of bug detection by the provider at time 0 and $b$ is the cost saving for each bug detected by the provider [15]. 
, where $w$ captures the per unit cost of monitoring. If the client finds that the provider has inflated his effort level, the client will impose a cheating penalty $\phi(\hat{e}-e)^{+} s$, where $(x)^{+}=\max \{0, x\}$. This penalty can also be regarded as the cost of reputation loss and the subsequent future business loss.

The timing of events is as follows. At Stage 0 , the client selects contract type, and if fixed-price contract is chosen, the client determines the contract term $\left\{F_{F P}\right\}$; if time-and-materials contract is chosen, the client determines contract terms $\left\{F_{T M}, r, \phi\right\}$. At Stage 1, the provider decides the effort level $e$ as well as the initial testing time $t$ in a fixed-price contract, or the effort level $e$ input to develop the system, the reported effort level $\hat{e}$ and initial testing time $t$ in a time-andmaterials contract.

At Stage 2, the system will have been developed and the uncertainty associated with the total number of bugs $N$ will have been realized. The parties renegotiate the initial testing time $t$ to a new one at $\tilde{t}$, and split the renegotiation surplus with the provider, thus getting a fraction $\alpha$ of it.

At Stage 3, according to the renegotiated testing time $\tilde{t}$, the provider will detect and fix the system bugs in the period $[0, \tilde{t}]$. Then, at Stage 4 , the system will be delivered to the client and the provider will offer system maintenance service.

\section{Contract Analysis}

We next examine the decisions of the client and the provider under a fixed-price contract and a time-andmaterials contract with renegotiation one-at-a-time.

\subsection{Fixed-Price Contract}

Under a fixed-price contract, the client first determines the payment $F_{F P}$ for software outsourcing services at Stage 0 . After observing the payment, the provider decides the initial testing time $t$ and exerts effort $e$ to develop the system at Stage 1. After system development, the two parties revise the initial testing time $t$ to $\tilde{t}$, and then the provider offers system testing and system maintenance services.

By backward induction, at Stage 2 the renegotiation surplus $\Delta \pi$ can be written as:

$$
\Delta \pi(\tilde{t})=(-k \tilde{t}-b N \exp (-\lambda \tilde{t}))-(-k t-b N \exp (-\lambda t))
$$

Optimizing Equation 5 over $\tilde{t}$, we obtain the optimal renegotiated testing time:

$$
\tilde{t}=(1 / \lambda) \ln (\lambda b N / k)
$$

At Stage 1, given the fixed payment $F_{F P}$, the expected payoff for the provider are as follows, where superscript $F P$ represents fixed-price contract and subscript $P$ represents the provider.

$$
\begin{aligned}
\pi_{P}^{F P}\left(e, t ; F_{F P}\right)= & \mathrm{E}_{\delta}\left[F_{F P}-c e^{2}-k t+\alpha \Delta \pi\right. \\
& \left.-(a+b \exp (-\lambda t))\left(N_{0}-e+\varepsilon\right)\right]
\end{aligned}
$$

At Stage 0 , anticipating the provider's response in effort level and initial testing time, the client determines the payment $F_{F P}$ to maximize its own profits as follows. Subscript $C$ represents the client.

$$
\pi_{C}^{F P}\left(F_{F P}\right)=\mathrm{E}_{\varepsilon}\left[V-u\left(N_{0}-e^{*}+\varepsilon\right)-F_{F P}+(1-\alpha) \Delta \pi\right]
$$

Assume the provider's reservation profit is 0 , and the individual rationality (IR) constraint is $\pi_{P}^{F P} \geq 0$, which guarantees the minimum expected payoff of the provider to accept the contract. Define the thresholds, $l_{1}=k\left(\ln \left(N_{0}-e_{L}\right)-\ln \left(N_{0}-e_{H}\right)\right) / \lambda\left(e_{H}-e_{L}\right)$ and $l_{2}=k\left(\eta\left(e_{L}\right)-\eta\left(e_{H}\right)\right) / 2 \varphi \lambda\left(e_{H}-e_{L}\right)$ , where $\eta(e)=\left(N_{0}-e+\varphi\right) \ln \left(N_{0}-e+\varphi\right)-\left(N_{0}-e-\varphi\right) \ln \left(N_{0}-e-\varphi\right)$. Here, the expression $l_{2}-l_{1}$ depicts the renegotiation surplus relative to effort. We further define a threshold for the provider's bargaining power as $\alpha^{H}=\left(c\left(e_{H}+e_{L}\right)-a-l_{1}\right) /\left(l_{2}-l_{1}\right)$. Then, maximizing Equations 7 and 8 , we obtain: ${ }^{2}$

- Proposition 1 (Fixed-Price Contract Effort and Testing Time) In a fixed-price contract, (i) if $0<c \leq\left(a+l_{1}\right)\left(e_{H}+e_{L}\right)$, and $\left(a+l_{1}\right)\left(e_{H}+e_{L}\right)<c \leq\left(a+l_{2}\right)\left(e_{H}+e_{L}\right)$, $\alpha^{H}<\alpha<1$, then the optimal effort level $e^{F P}=e_{H}$ and the optimal initial testing time

$$
\begin{aligned}
& t^{F P}=\ln \left(\lambda b\left(N_{0}-e_{H}\right) / k\right) / \lambda \text {; (ii) if } c>\left(a+l_{2}\right)\left(e_{H}+e_{L}\right) \\
& \text { and }\left(a+l_{1}\right)\left(e_{H}+e_{L}\right)<c \leq\left(a+l_{2}\right)\left(e_{H}+e_{L}\right), 0<\alpha<\alpha^{H} \text {, then } \\
& e^{F P}=e_{L} \text { and } t^{F P}=\ln \left(\lambda b\left(N_{0}-e_{L}\right) / k\right) / \lambda .
\end{aligned}
$$

Proposition 1 shows that $l_{2}-l_{1}>0$, which means that the renegotiation surplus increases in the provider's effort in the system development stage. Thus, in turn, when the provider's development efficiency is moderate and the provider has high bargaining power in renegotiation, the provider ought to be willing to exert a high level of effort to obtain more benefit from renegotiation. In other words, renegotiation can incentivize the provider's effort, and as the provider's bargaining power increases, it is more willing to exert effort.

\footnotetext{
${ }^{2}$ All modeling analysis, unless stated, is in the Appendix.
} 


\subsection{Time-and-Materials Contract}

In a time-and-materials contract, the client first determines the fixed payment $F_{T M}$, the per effort reward $r$ and the monitoring policy $\phi$. Then, the provider decides his effort level $e$, the reported effort level $\hat{e}$ and the initial testing time $t$. After the total number of system bugs $N$ has been recognized, both parties renegotiate initial testing time to $\tilde{t}$, and share the renegotiation surplus according to their relative bargaining power. Thus, given the contract terms $\left\{F_{T M}, r, \phi\right\}$, the expected payoff for the provider, with superscript $T M$ representing a time-and-materials contract, is:

$$
\begin{aligned}
\pi_{P}^{T M}\left(e, \hat{e}, t ; F_{F P}, r, \phi\right)= & \mathrm{E}_{\varepsilon}\left[F_{T M}+r \hat{e}-\phi s(\hat{e}-e)^{+}-c e^{2}-k t\right. \\
& \left.-(a+b \exp (-\lambda t))\left(N_{0}-e+\varepsilon\right)+\alpha \Delta \pi\right]
\end{aligned}
$$

Anticipating the provider's best response, the client determines $\left\{F_{T M}, r, \phi\right\}$ to maximize profit via: ${ }^{3}$

$$
\begin{gathered}
\pi_{C}^{T M}\left(F_{T M}, r, \phi\right)=\mathrm{E}_{\varepsilon}\left[V-u\left(N_{0}-e^{*}+\varepsilon\right)-F_{T M}-r \hat{e}^{*}\right. \\
-w \phi+(1-\alpha) \Delta \pi]
\end{gathered}
$$

Note that in addition to the IR constraint, $\pi_{P}^{T M} \geq 0$, the client further faces incentive compatibility (IC) constraints, $\pi_{P}^{T M}\left(e_{i}, \hat{e}_{i}, t^{*}\right) \geq \pi_{P}^{T M}\left(e_{i}, \hat{e}_{j}, t^{*}\right)(i, j=H \operatorname{or} L ; i \neq j)$, which ensure the provider is telling the truth about effort. Maximizing Equations 9 and 10, we obtain the optimal decisions of the two parties under the timeand-materials contract in Proposition 2.

- Proposition 2 (Time-and-Materials Contract Initial Testing Time and Monitoring Policy). In a time-and-materials contract,

(i) if $0<w<\left(u-s+(1-\alpha)\left(l_{2}-l_{1}\right)\right)\left(e_{H}-e_{L}\right)$ and $\frac{a+(1-\alpha) l_{1}+\alpha l_{2}}{e_{H}+e_{L}}$ $<c<\frac{a+s+(1-\alpha) l_{1}+\alpha l_{2}}{e_{H}+e_{L}}$, then the optimal initial testing time $t^{T M}=\ln \left(\lambda b\left(N_{0}-e_{H}\right) / k\right) / \lambda$, the optimal effort level $e^{T M}=e_{H}$, and the optimal monitoring policy $\phi^{T M}=1$;

(ii) if $w \geq\left(u-s+(1-\alpha)\left(l_{2}-l_{1}\right)\right)\left(e_{H}-e_{L}\right) \quad$ and $\frac{a+(1-\alpha) l_{1}+\alpha l_{2}}{e_{H}+e_{L}}<c<$ $\frac{a}{e_{H}+e_{L}}+\frac{u s\left(e_{H}+e_{L}\right)+\left((1-\alpha) l_{1}+\alpha l_{2}\right) w+s\left(e_{H}-e_{L}\right) l_{2}}{\left(w+s\left(e_{H}-e_{L}\right)\right)\left(e_{H}-e_{L}\right)}$, then $t^{T M}=\ln \left(\lambda b\left(N_{0}-e_{H}\right) / k\right) / \lambda \quad, \quad e^{T M}=e_{H} \quad, \quad$ and $\phi^{T M}=\frac{\left(u+(1-\alpha)\left(l_{2}-l_{1}\right)\right)\left(e_{H}-e_{L}\right)}{w+s\left(e_{H}-e_{L}\right)} ;$

(iii) if $0<c \leq \frac{a+(1-\alpha) l_{1}+\alpha l_{2}}{e_{H}+e_{L}}$, then $t^{T M}=\frac{1}{\lambda} \ln \left(\frac{\lambda b\left(N_{0}-e_{H}\right)}{k}\right)$, $e^{T M}=e_{H}$, and $\phi^{T M}=0$;

\footnotetext{
${ }^{3}$ The penalty for cheating $\phi s(\hat{e}-e)^{+}$is the cost of reputation loss and future business loss for the provider, but does not enter into the
}

(iv) otherwise, then $t^{T M}=\frac{1}{\lambda} \ln \left(\frac{\lambda b\left(N_{0}-e_{L}\right)}{k}\right), e^{T M}=e_{L}$, and $\phi^{T M}=0$.

Proposition 2 suggests that, apart from renegotiation, in the time-and-materials contract, the client can stimulate the provider's effort via monitoring. When the increased renegotiation surplus generated by the provider's effort cannot cover the development cost directly associated with the provider's effort, the provider will exert a low level of effort to develop the system. However, meanwhile, the high level of effort may create more profit for the client than a low level of effort will. This leads the client to incentivize the provider by implementing a policy with a high degree of monitoring for the time-and-materials contract. On the other hand, if the provider has high (low) development efficiency, where it is easier (more difficult) for the provider to improve system quality, the client's monitoring policy $\phi^{T M}=0$ and a time time-and-materials contract degenerates into a fixed-price contract.

\section{Contract Choice}

We now examine the contract choice between fixed-price and time-and-materials contracts for the client. Comparing the client's profit in the two contract types, we offer the third proposition. We define another two thresholds for the provider's bargaining power, $\alpha^{L}=\left(c\left(e_{H}+e_{L}\right)-a-s-l_{1}\right) /\left(l_{2}-l_{1}\right)$ and $\alpha^{M}=1-u s\left(e_{H}-e_{L}\right) /\left(\left(l_{2}-l_{1}\right) w\right)$ $+\left(w+s\left(e_{H}-e_{L}\right)\right)\left(c\left(e_{H}+e_{L}\right)-a-l_{2}\right) /\left(\left(l_{2}-l_{1}\right) w\right)$, and a threshold for the per unit cost of monitoring, $\hat{w}=\left(u+a+l_{2}-c\left(e_{H}+e_{L}\right)\right)\left(e_{H}-e_{L}\right)$.

- Proposition 3 (Testing Time Renegotiation Contract Choice). When testing time renegotiation is considered, the client will choose a timeand-materials contract over a fixed-price contract if $0<w<\hat{w}, \max \left\{0, \alpha^{L}\right\}<\alpha<\min \left\{\alpha^{H}, 1\right\}$, or if $w \geq \hat{w}, \max \left\{0, \alpha^{M}\right\}<\alpha<\min \left\{\alpha^{H}, 1\right\} ;$ otherwise, $a$ fixed-price contract will be preferred.

Figure 1 illustrates the results of Proposition 3. When the provider has high bargaining power, as in Region I, renegotiation incentivizes the provider's effort and weakens the effect of monitoring in stimulating the provider's effort, which leads the client to choose a fixed-price contract. When the provider has low bargaining power and the per unit cost of monitoring is low, as in Region II, the effect of renegotiation for incentivizing the provider's effort is more limited. Thus, to obtain more benefit from renegotiation, the

client's profit function, since it is not an earnings benefit that the client gets in practice [10]. 
client will use monitoring as a complement to incentivize the provider's effort and a time-and-materials contract will become the preferred choice.

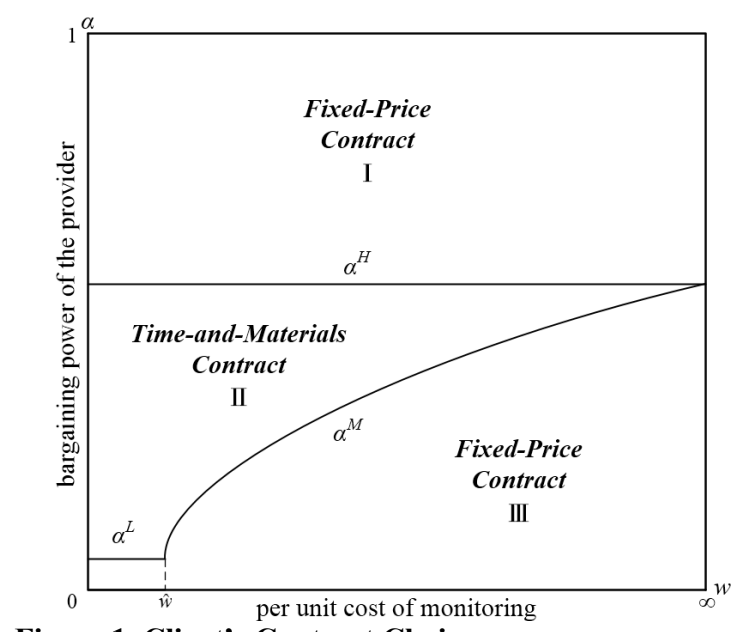

Figure 1. Client's Contract Choice

In Region III, when the provider has low bargaining power and the per unit cost of monitoring is high, at $\alpha^{L}<\alpha<\alpha^{M}$ and $w \geq \hat{w}$, again the beneficial effect of renegotiation to incentivize the provider's effort will be limited. Thus, to achieve more benefit from renegotiation, the client will reward a high value for $r$ to the provider to incentivize the provider's effort. However, high value of $r$ will lead to a high degree of monitoring with a high monitoring cost for the implementation of that policy. This reduces the benefit of monitoring, resulting in a different conclusion: a fixed-price contract is better than a time-and-materials contract.

Also $0<\alpha<\alpha^{L}$ equals $c \geq\left(a+s+(1-\alpha) l_{1}+\alpha l_{2}\right) /\left(e_{H}+e_{L}\right)$, which means that the provider's development efficiency is low. Thus, the provider will be reluctant to make an effort due to the high cost of development, and both renegotiation and monitoring cannot incentivize the provider's effort. Meanwhile, a time-andmaterials contract will degenerate into a fixed-price contract and the client will select the latter contract.

\section{Conclusion}

We established a multi-stage model where a client outsources a customized information system from a provider, and examined fixed-price and time-and-materials contracts. We focused on the impacts of testing time renegotiation on the client's preference for the contract types. Our analysis showed that compared with a fixed-price contract, a time-and-materials contract stimulates the provider's effort better due to monitoring. In both contracts, renegotiation can incentivize the provider's effort. As the provider's bargaining power in renegotiation increases, the provider is more willing to exert effort to develop the system. When the provider has high bargaining power, renegotiation offers a greater incentive and the client will prefer a fixed-price contract. When the provider has low bargaining power and the per unit cost of monitoring is low, however, the client will use monitoring to stimulate the provider and will choose a time-and-materials contract. And when the provider has low bargaining power and the per unit cost of monitoring is high, renegotiation leads to high monitoring cost, which causes the client to prefer a fixed-price contract.

Though research on software outsourcing contracts with renegotiation is in a nascent stage [2], there are a number of avenues that can be addressed by future research. To begin with, we assumed that renegotiation is costless. Future research should explore how renegotiation cost affects the client's contract choice. Next, it is of particular interest to investigate the impact of renegotiation on the value of information. Since the client can observe the performance of effort and renegotiate the initial contract ex post, the value of information will decrease. However, there is a possibility that the value of information will increase. This is because it can amplify the effect that the provider's private information reduces the client's profit, while renegotiation can increase the total surplus. Last, if there are two or more potential providers, then it is also interesting to study the effect of competition on the contract with renegotiation. This mimics real software outsourcing and has contract choice implications.

\section{Appendix A1. Fixed-Price Contract}

From Eqs. 5 and 6, Eqs. 7 and 8 can be written as:

$$
\begin{gathered}
\pi_{P}^{F P}\left(e, t ; F_{F P}\right)=F_{F P}-a\left(N_{0}-e\right)-c e^{2}-\frac{\alpha k}{\lambda}\left(\ln \left(\frac{\lambda b}{k}\right)+\frac{\eta(e)}{2 \varphi}\right) \quad(\mathrm{A} 1) \\
-(1-\alpha)\left(k t+b\left(N_{0}-e\right) \exp (-\lambda t)\right) \\
\pi_{C}^{F P}\left(F_{F P}\right)=V-u\left(N_{0}-e^{*}\right)-F_{F P}-\frac{(1-\alpha) k}{\lambda}\left(\ln \left(\frac{\lambda b}{k}\right)+\frac{\eta\left(e^{*}\right)}{2 \varphi}\right) \quad(\mathrm{A} 2) \\
+(1-\alpha)\left(k t^{*}+b\left(N_{0}-e^{*}\right) \exp \left(-\lambda t^{*}\right)\right)
\end{gathered}
$$

In Eq. A1, $t^{F P}$ is determined by FOC $\partial \pi_{P}^{F P} / \partial t=0$. Then substituting $t^{F P}=\frac{1}{\lambda} \ln \left(\frac{\lambda b\left(N_{0}-e\right)}{k}\right)$ into Equation A1 and comparing the value of $\pi_{P}^{F P}\left(e_{H}\right)$ and $\pi_{P}^{F P}\left(e_{L}\right)$, the optimal decisions for the provider can be derived. Next in Eq. A2, when the IR constraint binds, the client has maximal profit. So,

$$
\begin{aligned}
& F_{F P}=a\left(N_{0}-e^{F P}\right)+c e^{F P^{2}}+\frac{\alpha k}{\lambda}\left(\ln \left(\frac{\lambda b}{k}\right)+\frac{\eta\left(e^{F P}\right)}{2 \varphi}\right)+ \\
& (1-\alpha)\left(k t^{F P}+b\left(N_{0}-e^{F P}\right) \exp \left(-\lambda t^{F P}\right)\right) . \\
& \text { We next define the function: } f(e)=\frac{\eta(e)}{2 \varphi}-\ln \left(N_{0}-e\right) \text {. By the } \\
& \text { Hadamard inequality, we have } \frac{1}{2 \varphi} \int_{-\varphi}^{\varphi} \frac{1}{N_{0}-e+\varepsilon} \mathrm{d} \varepsilon>\frac{1}{N_{0}-e},
\end{aligned}
$$


where $\int_{-\varphi}^{\varphi} \frac{1}{N_{0}-e+\varepsilon} \mathrm{d} \varepsilon=\ln \left(N_{0}-e+\varphi\right)-\ln \left(N_{0}-e-\varphi\right)$. Therefore, $\frac{\partial f(e)}{\partial e}=\frac{1}{N_{0}-e}-\frac{1}{2 \varphi}\left(\ln \left(N_{0}-e+\varphi\right)-\ln \left(N_{0}-e-\varphi\right)\right)<0$. And then, $f\left(e_{L}\right)-f\left(e_{H}\right)>0$, which suggests that $l_{2}-l_{1}>0$.

\section{Appendix A2. Time-and-Materials Contract}

From Eqs. 5 and 6, Eqs. 9 and 10 can be written as:

$$
\begin{aligned}
& \pi_{P}^{T M}\left(e, \hat{e}, t ; F_{T M}, r, \phi\right)=F_{T M}+r \hat{e}-\phi s(\hat{e}-e)^{+}-a\left(N_{0}-e\right)-c e^{2} \\
&-(1-\alpha)\left(k t+b\left(N_{0}-e\right) \exp (-\lambda t)\right) \\
&-\frac{\alpha k}{\lambda}\left(\ln \left(\frac{\lambda b}{k}\right)+\frac{\eta(e)}{2 \varphi}\right) \\
& \pi_{C}^{T M}\left(F_{T M}, r, \phi\right)=V-u\left(N_{0}-e^{*}\right)-F_{T M}-r e^{*}-\frac{(1-\alpha) k}{\lambda}\left(\ln \left(\frac{\lambda b}{k}\right)+\frac{\eta\left(e^{*}\right)}{2 \varphi}\right)( \\
&+(1-\alpha)\left(k t^{*}+b\left(N_{0}-e^{*}\right) \exp \left(-\lambda t^{*}\right)\right)-w \phi
\end{aligned}
$$

First, the IC constraints should be satisfied, because the client prefers to deter the developer from cheating. Thus, the client offers an incentive compatible contract with $r \leq \phi s$. In Eq. A3, due to the constraints $r \leq \phi s$, we have $\hat{e}^{T M}=e^{T M} \cdot t^{T M}$ is determined by the first-order condition $\partial \pi_{P}^{T M} / \partial t=0$. Then substituting $\hat{e}=e$ and $t^{T M}=\frac{1}{\lambda} \ln \left(\frac{\lambda b\left(N_{0}-e\right)}{k}\right)$ into Eq. A3 and comparing the value of $\pi_{P}^{T M}\left(e_{H}\right)$ and $\pi_{P}^{T M}\left(e_{L}\right)$, the optimal decision for the provider can be derived. Next in Equation A4, the IR constraint is binding, so then we have the optimal payment $F^{T M}$. The constraint (IC-L) is binding so that $r^{T M}=\phi^{T M} S$ is observed. And substituting $\left(F^{T M}, r^{T M}, e(\phi)^{T M}, \hat{e}^{T M}, t^{T M}\right)$ into Eq. A4, we have:

$\max _{\phi} \pi_{C}^{T M}=V-(u+a)\left(N_{0}-e(\phi)^{T M}\right)-c e(\phi)^{T M^{2}}-w \phi-\frac{k}{\lambda}\left(\ln \left(\frac{\lambda b}{k}\right)+\frac{\eta\left(e(\phi)^{T M}\right)}{2 \varphi}\right)(\mathrm{A} 5)$.

Solving Eq. A5, the optimal decisions for the client in a time-and-materials contract then can be derived.

\section{References}

[1] August, T., and M. F. Niculescu. The influence of software process maturity and customer error reporting on software release and pricing. Mgmt. Sci., 59(12), 2013, 2702-2726.

[2] Benaroch, M., Dai, Q., and Kauffman, R.J. Should we go our own way? Analyzing backsourcing flexibility in it service outsourcing contracts. J. Mgmt. Info. Sys., 26(4), 2010, 317-358.

[3] Benaroch, M., Y. Lichtenstein, and L. Fink. Contract design choices and the balance of ex ante and ex post transaction costs in software development outsourcing. MIS Qtrly., 40(1), 2016, 57-82.

[4] Bhattacharya, S., A. Gupta, and S. Hasija. Joint product improvement by client and customer support center: The role of gain-share contracts in coordination. Info. Sys. Res., 25(1), 2014, 137-151.

[5] Bolton, P., and M. Dewatripont. Contract Theory. MIT Press, Cambridge, 2005.

[6] Cezar, A., H. Cavusoglu, and S. Raghunathan. Outsourcing information security: Contracting issues and security implication. Mgmt. Sci., 60(3), 2014, 638-657.
[7] Che, Y. K., and D. B. Hausch. Cooperative investments and the value of contracting. Amer. Econ. Rev., 89(1), 1999, 125-147.

[8] Chen, Y., and A. Bharadwaj. An empirical analysis of contract structures in IT outsourcing. Info. Sys. Res., 20(4), 2009, 484-506.

[9] Dequiedt, V., and Martimort, D. Vertical contracting with informational opportunism. Amer. Econ. Rev., 105(7), 2015, 2141-82.

[10] Dey, D., M. Fan, and C. L. Zhang. Design and analysis of contracts for software outsourcing. Info. Sys. Res, 21(1), 2010, 93-114.

[11] Fitoussi, D., and V. Gurbaxani. IT outsourcing contracts and performance measurement. Info. Sys. Res, 23(1), 2012, 129-43.

[12] Goltsman, M. Optimal information transmission in a holdup problem. RAND J. Econ., 42(3), 2011, 495-526.

[13] Gopal, A., and K. Sivaramakrishnan. On vendor preferences for contract types in offshore software projects: The case of fixed price vs. time and materials contracts. Info. Sys. Res, 19(2), 2008, 202-220.

[14] Hart, O. D., and J. Tirole. Contract renegotiation and Coasian dynamics. Rev. Econ. Stud., 55(4), 1988, 509540.

[15] Jiang, Z., S. Sarkar, and V. S. Jacob. Postrelease testing and software release policy for enterprise-level systems. Info. Sys. Res., 23(3-part-1), 2012, 635-657.

[16] Jiang, Z., K. P. Scheibe, S. Nilakanta, and X. Qu. The economics of public beta testing. Dec. Sci., 48(1), 2017, 150-175.

[17] Knoll, L. 5 reasons to love time \& material and avoid the fixed-price model. Brainhub.eu, Warsaw, 2016.

[18] KPMG. Global IT-BPO outsourcing deals analysis: Annual analysis for 2016. London, 2017.

[19] Krishnan, M. S., Mukhopadhyay, T., and Kriebel, C. H. A decision model for software maintenance. Info. Sys. Res., 15(4), 2004, 396-412.

[20] Lee, C. H., X. J. Geng, and S. Raghunathan. Contract information security in the presence of double moral hazard. Info. Sys. Res., 24(2), 2013, 295-311.

[21] Liang, H. G., Wang, J. J., Xue, Y. J., and Cui, X. C. IT outsourcing research from 1992 to 2013: A literature review based on main path analysis. Info. \& Mgmt., 53(2), 2016, 227-251.

[22] Marso, A. Behind the backlog: The problem-plagued rollout of KEES. Kansas Health Inst., Topeka, 2016.

[23] Mathur, N. Vodafone India renews IT deal with IBM for five years. Livemint.com, Bangalore, 2016.

[24] Moreno, H. How IT service management delivers value to the digital enterprise. Forbes, March 16, 2017.

[25] Pham, H., X. Zhang. Software release policies with gain in reliability justifying the costs. Ann. Softw. Eng., 8(1), 1999, 147-166.

[26] SSON News and Analysis. Top ten tips for a smooth contract renegotiation. London, 2012.

[27] Susarla, A. Contractual flexibility, rent seeking, and renegotiation design: Empirical analysis of IT outsourcing contracts. Mgmt. Sci., 58(7), 2012, 1388-1407.

[28] TechNavio. Global IT outsourcing market 2015-2019. London, 2015 